\title{
LETRAMENTO LITERÁRIO E CULTURAL NA FORMAÇÃO DO PROFES- SOR E ALUNO
}

\author{
Tania Pleszko Janusis ${ }^{1}$
}

\section{RESUMO}

O ser letrado consegue fazer uso competente da leitura e escrita nos mais variados gêneros textuais, nível de linguagens e de acordo com as demandas sociais e linguísticas da nossa língua e cultura. Por essa razão, o letramento se faz mais que necessário para a formação docente, uma vez que o educador influencia na formação de seus alunos e contribui para a formação de uma sociedade mais crítica e democrática. No que tange o acercamento aos textos literários, devido eles prezarem pela estética textual e pela subjetividade, visando construir narrativas baseadas em acontecimentos corriqueiros, memórias, reflexões e outras fontes de inspiração para o autor, podem acercar o leitor de textos que exploram culturas e experiências riquíssimas, para nossa formação e conhecimento de mundo, além de estreitar o apreço pela leitura, uma vez que no geral, são narrativas cronológicas e contínuas. Por outro lado, sabe-se que educadores ingressam no mercado de trabalho sem um domínio eficaz da nossa língua e de seus preceitos, em especial, no que tange ao letramento literário, social e cultural, uma vez que o manejo eficaz da linguagem (leitura, escrita e interpretação crítica dos mais variados gêneros e tipologias textuais) propicia a emancipação do homem. Por tais motivos, acredita-se que na formação de educadores estes norteadores são ainda mais essenciais.

Palavras-Chave: Formação de Professores. Letramento. Gêneros Textuais. Criticidade Literária.

\begin{abstract}
The literate being manages to make competent use of reading and writing in the most varied textual genres, level of languages and according to the social and linguistic demands of our language and culture. For this reason, literacy is more than necessary for teacher education, since the educator influences the education of his students and contributes to the formation of a more critical and democratic society. Regarding the approach to literary texts, because they value textual aesthetics and subjectivity, aiming to build narratives based on common events, memories, reflections and other sources of inspiration for the author, they can approach the reader of texts that explore cultures and experiences very rich, for our formation and knowledge of the world, in addition to narrowing the appreciation for reading, since in general, they are chronological and continuous narratives. On the other hand, it is known that educators enter the labor market without an effective command of our language and its precepts, especially with regard to literary, social and cultural literacy, since the effective management of language (reading, writing and critical interpretation of the most varied genres and textual typologies) provides the emancipation of man. For these reasons, it is believed that in the training of educators, these guidelines are even more essential.
\end{abstract}

Keywords: Teacher Training. Literacy. Textual Genres. Literary Criticism.

\footnotetext{
1 Pedagoga e especialista em Neuropsicopedagogia (FAISP), professora da rede pública de São Paulo. E-mail: tania.13pj@gmail.com
} 


\section{RESUMEN}

El ser alfabetizado puede hacer un uso competente de la lectura y la escritura en los más variados géneros textuales, nivel de lenguas y de acuerdo con las demandas sociales y lingüísticas de nuestra lengua y cultura. Por esta razón, la alfabetización es más que necesaria para la formación del profesorado, ya que el educador influye en la formación de sus alumnos y contribuye a la formación de una sociedad más crítica y democrática. Con respecto a la proximidad a los textos literarios, debido a que valoran la estética textual y la subjetividad, con el objetivo de construir narrativas basadas en eventos ordinarios, recuerdos, reflexiones y otras fuentes de inspiración para el autor, pueden acercarse al lector de textos que exploran ricas culturas y experiencias, para nuestra formación y conocimiento del mundo, además de reducir el aprecio por la lectura, ya que en general, son narraciones cronológicas y continuas. Por otro lado, se sabe que los educadores entran en el mercado laboral sin un dominio efectivo de nuestra lengua y sus preceptos, especialmente en lo que se refiere a la alfabetización literaria, social y cultural, ya que la gestión eficaz del lenguaje (lectura, escritura e interpretación crítica de los más variados géneros textuales y tipologías) proporciona la emancipación del hombre. Por estas razones, se cree que en la formación de los educadores estos profesores son aún más esenciales.

Palabras clave: Formación Docente. Alfabetización. Géneros Textuales. Criticidad Literaria.

\section{INTRODUÇÃO}

No mundo em que vivemos ser letrado é um diferencial que favorece a democracia e propicia a vivência plena dos direitos de cada pessoa, por essa razão, na formação do docente será preciso trabalhar de forma crítica, coesa e coerente a questão do letramento literário e cultural, para que o professor se muna de conhecimentos, bases e saberes formais, capazes de permiti-lo semear estes conhecimentos para seus alunos.

Por outro lado, é importante lembrar que atualmente o perfil dos alunos são influenciados pelos diversos meios e formatos de textos e gêneros literários, influenciando em seu modo de analisar e de se relacionar com cada um deles, sejam escritos, musicados, imagéticos, hiper linkados e interativos. Além daqueles que estão cada vez mais presente nos meios de comunicação midiáticos e que e exploram a fantasia, a ficção e a tecnologia.

Isso reforça a necessidade de uma formação docente solida e atualizada, ancorada numa abordagem teoria e didática capaz de suprir as necessidades e realidades do aluno da era conectada.

Tem-se como objetivo neste escrito discutir sobre a importância e contribuição do letramento e da cultura na formação e atuação prática dos docentes e discentes no seio escolar, no intuito de formar pessoas críticas e capazes de lidar com os mais completos tipos de textos e suas particularidades. Além de 
retratar a cultura como um fator capaz de potencializar e facilitar a relação do homem com o meio em que ele está inserido, transitando e dialogando com as mais variadas culturas, respeitando suas individualidades e usufruindo de suas contribuições para uma formação emancipadora, coesa e coerente.

Para sustentar os argumentos apresentados neste artigo recorreu-se a revisões bibliográficas de autores consagrados sobre o assunto em questão, no intuito de dar sustento às falas aqui apresentadas, de forma qualitativa.

\section{ENTENDENDO O LETRAMENTO LITERÁRIO}

O letramento literário visa designar a construção de sentido à partir da sua relação com a escrita, seu termo se relaciona de forma diferenciada com a escrita, uma vez que ocupa uma posição exclusiva no que tange à linguagem. Seu surgimento se deu pela necessidade de estruturar e caracterizar as práticas sociais e os comportamentos humanos através da leitura e escrita que, se sobressaem ao domínio do sistema alfabético e ortográfico.

O letramento literário ocorre de forma poderá da e transformadora, pois 0 gosto pela leitura nos seus mais diferentes tipos de textos não se dá exclusivamente por prazer, muitas vezes acontecem por necessidades de se cumprir com algum dever social, profissional ou acadêmicos-escolar. Assim sendo, o processo de letramento literário surgiu como uma prática social de humanização, sendo a escola a maior responsável por essa tarefa, acompanhada das famílias que é a maior parceira da escola no processo de formação dos docentes.

Ante a esse fato, caberá ao docente fortalecer o repertório crítico e literário do aluno, sempre apresentando a ele diferentes narrativas e diferentes graus de complexidade destas, levando-os a ultrapassarem o simples consumo do texto literário.

Vale lembrar que letramento literário se difere de alfabetização, uma vez que seu papel é o de levar o aluno já alfabetizado a interpretar e se relacionar com as particularidades mais críticas da língua, no intuito de aperfeiçoar e ampliar sua visão sobre a leitura, escrita, a cultura e os diferentes textos em suas complexidades. Para reforçar essa fala, recorreu-se aos estudos de Zappone (2008) que afirma que: 
A apropriação do conceito de letramento ao campo dos estudos literários pode ser pertinente, se operarmos uma modulação fundamental: trabalhar com a escrita mencionada no conceito, mas compreendida dentro de algumas especificidades concernentes aos textos literários. Assim, podemos acatar o conceito de letramento nos estudos literários, propondo a noção de letramento literário enquanto o conjunto de práticas sociais que usam a escrita literária (ZAPPONE, p. 29, 2008).

Cadê destacar também que a literatura no seio escolar torna-se um recurso de aproximação do discente com o texto, ao passo em que o letramento literário, acontece a partir de questionamentos destes textos, tais como: quem fala, quando fala, o que fala, como fala, para que fala e em que nível de linguagem fala. As respostas a estes questionamentos podem ser obtidas ao fazermos uma análise aprofunda e crítica da obra, condicionando os envolvidos à tarefa de ler e reler os textos. Desse modo, o letramento literário por se tratar de um mecanismo de transgressão no processo de ensino/aprendizagem da literatura, deve ser uma prática indispensável e contínua no processo de formação dos docentes e discentes.

Na prática docente, o letramento literário pode ocorrer de muitas formas, seja ela através de iniciativa própria do aluno com a obra, por incentivo e exemplo da família ou, por meio do auxílio do educador em sala de aula.

Outro ponto relevante a ser considerado deve se ao fato de o docente ter o discernimento de respeitar o interesse do aluno pela obra e sua faixa etária, para não errar na dose, no linguajar e nos conteúdos explícitos na obra, o que pode inibir o a relação do aluno com a leitura.

Indicar e ampliar o repertório literário do discente é mais uma tarefa do professor, levando em consideração o fato de que a literatura não se limita apenas aos textos escritos, mas se apresenta nas diversas manifestações culturais humanas (musical, visual, escrita, oral...), e presente em muitos outros suportes e meios de comunicação.

As atividades com leitores tendo como objeto a leitura e precisam ser apresentadas aos alunos de forma a seguir uma sequência básica.

Motivação - Despertar no aluno o interesse pela leitura e seus encantos. Introdução - Apresentar a obra para o aluno e fazer a intermediação entre o autor, o conteúdo e o aluno. 


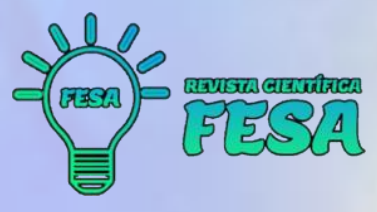

Leitura - Momento em que o docente tem a oportunidade de conhecer as limitações e necessidades de ajustes no processo de aperfeiçoamento de leitura do seu aluno.

Interpretação - Momento oportuno para ler as entrelinhas e debater sobre as mensagens ocultas e subjetivas num determinado texto, favorecendo a criticidade e o diálogo entre o leitor e a obra em estudo

Dessa forma, nos valemos da visão dos DCEs, que reforçam que:

Nos textos de literatura, as reflexões sobre a ideologia e a construção da realidade fazem parte da produção do conhecimento, sempre parcial, complexo e dinâmico, dependente do contexto e das relações de poder. Assim, ao apresentar textos literários aos alunos, devem-se propor atividades que colaborem para que ele analise os textos e os perceba como prática social de uma sociedade em um determinado contexto sociocultural (DCEs, p. 67, 2009).

\title{
PAPEL E CONTRIBUIÇÃO DA LEITURA NA VIDA E FORMAÇÃO DO SER HUMANO
}

O processo de formação de leitores deve ser iniciado desde cedo, se estendendo por toda a vida humana. $E$ isso é importante pois 0 ato de ler liberta $o$ homem e o capacita para interagir de maneira crítica, clara e objetiva em seu meio.

Acerca dessa afirmação Grossi (2008) afirmar que:

\begin{abstract}
Pessoas que não são leitoras têm a vida restrita à comunicação oral e dificilmente ampliam seus horizontes, por ter contato com ideias próximas das suas, nas conversas com amigos. [...] é nos livros que temos a chance d entrar em contato com o desconhecido, conhecer outras épocas e outros lugares - e, com eles abrir a cabeça. Por isso, incentivar a formação de leitores é não apenas fundamental no mundo globalizado em que vivemos. É trabalhar pela sustentabilidade do planeta, ao garantir a convivência pacífica entre todos e o respeito à diversidade (GROSSI, p.3, 2008).
\end{abstract}

A leitura permite compreender a cultura e seu papel na sociedade, tanto no processo de libertação, quanto no da reconstrução nacional. É um passo que se dá a procura de saber mais, sem esquecer nunca que é praticando que se aprende.

Estudar é um dever revolucionário, criar e recriar, criticar e aceitar críticas, pensar certo e desenvolver a curiosidade perante a realidade.

\section{CONERGÊNCASTEÓRCASDOMNDOCONIEMPORÂNEO}


Conforme Todorov (2010):

Os livros acumulam a sabedoria que os povos de toda a terra adquiriram ao longo dos séculos. É improvável que a minha vida individual, então poucos anos, possa ter tantas riquezas quanto a soma de vidas representadas pelos livros. Não se tratar de substituir a experiência pela literatura, mas multiplicar uma pela outra. Não lemos para nos tornar especialistas em teoria literária, mais para aprender mais sobre a existência humana. Quando lemos, nos tornamos antes de qualquer coisa especialistas em vida. Adquirimos uma riqueza que não está apenas no acesso as ideias, mas também no conhecimento do ser humano em toda a sua diversidade (TODOROV, p. 38 - 39, 2010).

Como cenário acima mencionado, torna-se imprescindível a aquisição da leitura e seu entendimento global, para poder realmente está inserido na sociedade como cidadão que exerce sua cidadania. Para tanto, é necessário que a leitura faça parte real e cotidiana de nossa vida.

Por fim cabe reforçar que, a ação de ler não é dita apenas decodificar as palavras, mas atribuir sentido ao texto, compreendendo e interpretando as relações com o contexto social, com o que já foi vivido. Tal qual afirma Ferreiro e Teberosky (1999, p. 37) ler não equivale a decodificar as grafias em sons e que, portanto, a leitura não pode ser reduzida a puro decifrado.

Segundo Hansen (2005), os programas de leitura escolar estão cientes da especificidade literária, tanto que a discernem de outras leituras e descrevem como deve ser desenvolvida:

\begin{abstract}
É um pressuposto deles que, por ser gratuita, não-pragmática ou interessadamente desinteressada, a leitura de ficção deverá levar o leitor escolar a objetivar sua experiência individual, pondo-se a si mesmo entre parênteses como sujeito social de hábitos perceptivos quando faz a experiência da liberdade imaginária dos possíveis da ficção. Nos programas, essa experiência de auto-distanciamento e relativização do vivido imediato é, como disse, descrita genericamente como "atitude crítica", "reflexão", "auto-conhecimento", "conhecimento da realidade do país" etc. Conforme essas orientações, a leitura literária teria a função de desautomatização de hábitos, formação crítica do imaginário, esclarecimento democrático, aculturação e socialização do estudante. Contrastando tecnicamente com a leitura pragmática e a leitura científica, seria antes de tudo crítica, opondo-se politicamente à ideologia (HANSEN, p. 42, 2005).
\end{abstract}

A citação em questão atesta que Hansen considera que nossos programas escolares atestam a importância da literatura para a formação crítica dos discentes.

\title{
CONGRGÂAAASTECÓRCASDOMNDOCONIEMPORÂNEO
}




\section{FASES DO PROCESSO DE LEITURA}

Como já discorrido, o ato de ler vai muito além de conhecer e decifrar as letras, requer conhecimento das particularidades das palavras, dos tipos de textos e dos gêneros estudados, para assim, ter domínio dos códigos, signos e a linguagens que estão embutidas neste processo.

Cabe recordar que o ato de ler desde pequeno é de grande valia para o desenvolvimento destas habilidades no futuro, estimulando a criatividade, e criticidade do discente, pois a leitura é importante para o desenvolvimento cognitivo do aluno e, é através dela que o indivíduo adquire conhecimento sobre o mundo e suas epopeias. Portanto, é de suma importância que a formação leitora e escrita da criança inicie desde cedo, e para que isso se torne real, é facultativo que as famílias se disponham a ler para seus filhos incentivando-os a adquirir este hábito e ampliar assim, suas possibilidades de aprendizagem sobre a diversidades da língua em uso.

O exemplo que a criança tem em casa é o mais valioso, por isso quando ela vir os pais em diversas oportunidades "agarrados" a livros ou mesmo periódicos, terá maior facilidade a valorizar tal ato instintivamente. (SANDRONI L. C.; MACHADO L. R, 1987).

Entendemos que 0 ato de ler compreenda ao menos dois estágios: visualizar a palavra e levá-la em consideração de acordo com informações já conhecidas (interpretar).

Uma vez que as informações transmitidas aos olhos percorrem até o um conglomerado de neurônios especializados(cérebro), cada um destes conglomerados ocupam e desempenham uma função específica em uma parte no cérebro. Portanto, ler não se restringe à um processo "automático" de aquisição de um texto, e sim, processo de ressignificação e reconstrução do signo e códigos, no qual apenas um significado estará correto, em outras palavras, um processo generativo que reflete a tentativa disciplinada do leitor para construir múltiplos significados no seio da linguagem, a partir de normas estabelecidas. 


\section{A CULTURA E SEU IMPACTO NO PROCESSO DE APRENDIZAGEM}

A cultura é fruto das ações de cada povo, por isso, todo individuo possui sua própria cultura, influenciada pelo seu meio e relações.

No âmbito escolar, se faz necessário valorizar e reconhecer as diferentes culturas e, trabalhar para que todos os alunos possam ser inseridos e se relacionarem com a cultura do seu entorno, usufruindo de todo potencial que ela pode propiciar a eles. Dessa forma, é preciso que os docentes saibam lidar com particularidades advindas de fatores como a língua, posturas corporais, preferências, ritmos de falas, ente outros.

Sobre essa visão BOURDIEU afirma que: "a cultura é o conteúdo substancial da educação, sua fonte e sua justificação última [...] uma não pode ser pensada sem a outra"

Frente a esse posicionamento, a cultura se porta como um elemento que alimenta todo o processo educacional, por essa razão, é facultativo que seja reconhecida a multiculturalidade social e que se valorize a diversidades culturais presentes no contexto escolar, já que a escola é um ambiente socializador e responsável por formar, desenvolver e favorecer a criticidade e a democracia dos envolvidos.

Reforçando o entendimento de cultura, Darcy Ribeiro (1972): afirma que:

[...] cultura é a herança social de uma comunidade humana, representada pelo acervo co-participado de modos padronizados de adaptação à natureza para o provimento da subsistência, de normas e instituições reguladoras das reações sociais e de corpos de saber, de valores e de crenças com que explicam sua experiência, exprimem sua criatividade artística e se motivam para ação (RIBEIRO, 1972).

Essa fala nos mostra que cultura e a educação são fenômenos intrinsecamente interligados e que contribuem para o progresso de ambos. Dessa forma, fica evidente que as relações entre cultura e escola não devem ser tidas como fatores independentes, mas sim como universos entrelaçados e que podem se aixiliar no desenvovimento do homem.

Diante dessa constatação Candau e Anhorn (2000, p.2) afirmam que "hoje se faz cada vez mais urgente a incorporação da dimensão cultural na prática 
pedagógica". Os mesmos autores seguem tratando do assunto e enfatizando que:

[...] um currículo multicultural coloca aos professores o desafio de encontrar estratégias e recursos didáticos para que os conteúdos advindos de variadas culturas sejam utilizados como veículo para: introduzir ou exemplificar conceitos relativos a uma ou outra disciplina; ajudar os alunos a compreender e investigar como os referenciais teóricos de sua disciplina implicam na construção de determinados conhecimentos; facilitar o aproveitamento dos alunos pertencentes a diferentes grupos sociais; estimular a auto-estima de grupos sociais minoritários ou excluídos; educar para o respeito ao plural, ao diferente, para o exercício da democracia, enfatizando ações e discursos que problematizem e enfraqueçam manifestações racistas, discriminatórias, opressoras e autoritárias, existentes em nossa nossas práticas sociais cotidianas (CANDAU; ANHORN, 2000).

Concluí-se assim que, a inclusão da disciplina multicultural no seio escolar, bem como o trabalho sobre as diferentes culturas e sua importância para a formação do docente e do discente, ampliando suas visões sobre outras culturas e sobre a própria formação crítica e social.

\section{CONSIDERAÇÕES FINAIS}

Conforme discutido neste artigo, trabalhar o letramento dos docentes e discentes é de grande importância para desenvolvermos uma sociedade mais crítica, justa e capaz de exercer a cidadania em sua plenitude, pois o letramento capacita o homem para interpretar a língua em seus preceitos e particularidades, atravessando todos os horizontes linguísticos e do processo comunicativo.

Neste contexto, a cultura surge como um fator que tem o poder de levar às pessoas todo o potencial que ela carrega, seja na arte, na música, na comunicação, na expressão corporal, oral e escrita, já que ela é uma representação das ações do homem, o definindo pelas marcas e particularidades de um determinado grupo e suas ações. 


\section{REFERÊNCIAS BIBLIOGRÁFICAS}

BOURDIEU, P. Razões práticas: sobre a teoria da ação. Campinas: Papirus, 1996.

CANDAU, Vera Maria Ferrão. Educação escola e Cultura(s): construindo caminhos. Revista Brasileira de Educação, 2003.

CANDAU, Vera Maria Ferrão. Sociedade, cotidiano escolar e cultura(s): uma aproximação. Educ. Soc., 79: 125-161, 2002.

FERREIRA, Nilza Brandolfo, A relação Cultura e Educação. Projeto apresentado no curso de Pós-Graduação Lato Sensu: Psicopedagogia Clínica e Educacional a UNESP.São Paulo,2005

GROSSI, Gabriel Pillar. Leitura e sustentabilidade. Nova Escola, São Paulo, $\mathrm{SP}, \mathrm{n}^{\circ} 18$, abr. 2008.

JORDÃO. Letramentos e Multiletramentos no Ensino de Línguas e Literaturas. DOSSIÊ ESPECIAL. Revista X, vol.1, 2011.

HANSEN, J. A. Reorientações no campo da leitura literária. In: ABREU, M.; SCHAPOCHNIK, N. Cultura letrada no Brasil: objetos e práticas. Campinas, SP: mercado de Letras, ALB, São Paulo: Fapesp, 2005.

RIBEIRO, Darcy. O processo Civilizatório: Etapas da Evolução Sócio-Cultural. 10ํe․, Petrópolis: Vozes, 1972.

SANDRONI, L. C.; MACHADO, L. R. Ler em casa. In:_. A criança e o livro. 2. ed. São Paulo: Ática, 1987

TODOROV, Tzvetan. A literatura em perigo. Trad. Caio Meira. 3ª . Ed. Rio de Janeiro: DIFEL, 2010.

ZAPPONE, Mirian Hisae Yaegashi. Fanfics - um caso de letramento literário na cibercultura? Letras de Hoje, Porto Alegre, v. 43, n. 2, p. 29-33, abr./jun. 2008. 